\title{
Um idílio grego traduzido para o latim no Renascimento: critérios utilizados na época e propostas de tradução poética
}

Ricardo da Cunha Lima

Resumo: A partir da versão em latim de um idílio do poeta bucólico grego Teócrito, composta no século 16 pelo humanista português Antônio de Gouveia, foram desenvolvidas algumas reflexões acerca de critérios e modos de realização de uma tradução literária, que resultaram em duas diferentes propostas de tradução poética (em versos metrificados) do epigrama neolatino renascentista. Essas duas alternativas são extensamente discutidas e, ao final do artigo, apresentadas ao lado dos textos originais.

Palavras-chave: Tradução poética; Línguas Clássicas (Grego e Latim); Teócrito; Poesia Bucólica; Antônio de Gouveia; Epigrama; Dístico Elegíaco; Humanismo; Renascimento; Literatura Neolatina.

Uma das características do Renascimento foi a produção da poesia neolatina composta por humanistas que, imitando o estilo dos autores clássicos da Literatura Latina (como Ovídio ou Virgílio), escreviam poemas em latim, com a métrica, o vocabulário e todas as demais normas literárias dos antigos. Uma parte dessa produção consiste na versão em latim de poemas coevos, escritos originalmente nas línguas vernáculas, como francês ou inglês, ou então de poemas da Literatura Grega Antiga. Nesse último caso, tais traduções tinham 
pelo menos três propósitos: divulgar o repertório poético grego clássico numa língua de maior difusão no ambiente intelectual, indicar os modelos literários prediletos e revelar a maestria artística dos letrados, chancelando sua própria produção autônoma.

Dentre os humanistas que se dedicaram a esse tipo de produção literária, podemos apontar o português Antônio de Gouveia, que seguiu carreira acadêmica na França e participou, ao lado de Dolet, Saint-Gelais, Marot e Sébastien Gryphe, entre outros, do círculo literário de Lyon, onde publicou duas obras de poesia neolatina, nos anos de 1539 e 1540, intituladas, respectivamente, Epigrammaton Libri Duo e Epigrammata; Eiusdem Epistulae Quattuor. Em meio a sua obra epigramática, encontramos uma tradução para o latim do Idílio 19, de Teócrito. Este poema, intitulado Khriokle/ pthj ("Ladrão de mel"), tem a sua autoria atualmente contestada pelos estudos filológicos, mas, no século 16, prevalecia a tradição que o atribuía ao importante poeta bucólico grego. Esse idílio é composto por oito versos, todos hexâmetros dactílicos, metro preferencial de Teócrito.

Gouveia deu à sua tradução um título novo, Ictus Amor, isto é, "O Amor Ferido", e um novo metro, o dístico elegíaco, embora tenha mantido o total de oito versos, distribuídos em quatro dísticos.

Uma vez que nos temos ocupado da análise e tradução da obra poética de Antônio de Gouveia, vimo-nos diante de várias questões: de que maneira traduzir esse epigrama latino? Devemos incorporar os mesmos critérios utilizados pelo poeta ao verter o original grego? Seus procedimentos permitem reflexões úteis acerca da atividade de tradução? Podemos opor ao estilo de tradução relativamente livre e criativo, empregado pelo humanista, um outro estilo, mais preso aos elementos literários identificados na obra original a ser traduzida?

Essas questões nos conduziram a duas diferentes propostas de tradução poética. Elas têm em comum o emprego de versos metrificados - obedecendo a ritmos literários tradicionais da língua portuguesa - e a observação do total de oito versos para a composição. 
Na primeira proposta, procuramos imitar os procedimentos do humanista e aplicar, ao seu texto, as mesmas soluções que ele havia empregado anteriormente, diante da obra grega, como se déssemos a ele de seu próprio remédio. Nessa tentativa, a tradução do epigrama latino mantém, como referencial e pano de fundo permanente, o Idílio 19.

Investigando os elementos do poema latino e comparando-o com sua fonte grega, podemos notar que as principais características do procedimento de tradução/recriação de Gouveia são: a) criação de um novo título; b) manutenção do total de versos, mas com a alteração do metro original; c) obediência às convenções poéticas do novo metro; d) exploração de figuras retóricas características da poesia latina e do novo metro empregado; e) uso de recursos sonoros ausentes no original, com a criação, por exemplo, de novas aliterações; f) preocupação de apresentar o conteúdo semântico do original, mas com mudanças na importância de determinados aspectos, que foram enfatizados, reorientando sutilmente algumas idéias do texto original, ainda que a maior parte do vocabulário do grego seja retomada no latim.

A fim de imitar a tradução de Gouveia, adotamos várias de suas iniciativas, como a proposição de um novo título, a recriação de aliterações e a manutenção do enredo fundamental do texto. Para a escolha do vocabulário, voltamos ao original grego sempre que este proporcionava uma alternativa adequada, o que fez com que nossa versão se parecesse sensivelmente com o poema grego, por vezes até mais do que com a peça neolatina. Na escolha do metro, seguimos o critério do humanista: com efeito, o dístico elegíaco, escolhido por Gouveia, é o metro mais empregado por ele no restante de sua obra, e também o mais comum, na Literatura Latina, na composição de epigramas. Portanto, cumpria-nos escolher um metro tradicional da Literatura em Língua Portuguesa que representasse, em alguma medida, o apuro formal e a recorrência de uso do dístico elegíaco. Pareceu-nos que o decassílabo era o melhor equivalente da transposição efetuada por Gouveia (na substituição do hexâmetro

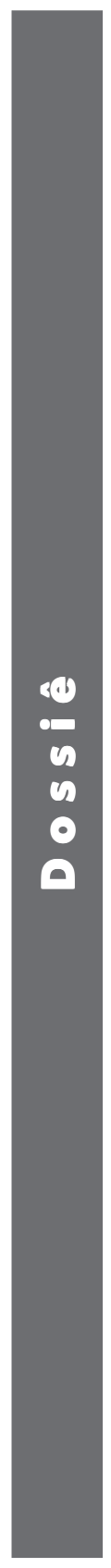


pelo dístico), em virtude da tradição que consolidou na nossa literatura. Por outro lado, mantivemos o total de oito versos, como fizera Gouveia com o poema de Teócrito. Cabe mencionar que chegamos a vislumbrar uma outra possibilidade, posteriormente descartada: converter o poema num soneto, atitude que também representaria, de certo modo, a conversão operada pelo quinhentista. $\mathrm{O}$ resultado de tais intenções apresenta-se, ao final do presente artigo, sob a rubrica “Tradução A" (intitulada “O Amor Ladrão").

Na segunda proposta, contudo, tomamos o epigrama Ictus Amor independente de referência ao idílio original grego e procuramos observar suas características poéticas particulares, buscando reproduzi-las e salientá-las na tradução.

Nesse sentido, verificamos que Gouveia, ao transpor o poema grego para o dístico elegíaco, respeitou, acima de tudo, as convenções estilísticas da nova forma. Um exemplo disso é que o poeta quinhentista usa o dístico como unidade interna, não havendo prolongamentos sintáticos de um dístico para outro: assim, cada dístico funciona como um período sintático, dando conta de um passo do desenvolvimento do poema. Dentro do dístico, o segundo verso, ou seja, o pentâmetro, obedece à rígida convenção da cesura, e o tradutor usa os hemistíquios resultantes da cesura de modo intencional, ou para criar antíteses no interior dos hemistíquios (como em frigidulo ignitum, no verso 4, ou magna perexiguae, no verso 6), ou para criar oposições dicotômicas entre as duas metades do verso, como nos versos 2 e 4 .

No intuito de reproduzir o dístico elegíaco na língua portuguesa, pareceu-nos que o melhor equivalente do pentâmetro (i.e. o segundo verso) seria o dodecassílabo alexandrino, em função da mesma cesura intermédia existente no pentâmetro latino, com a pausa marcada pela sexta sílaba acentuada. De fato, tanto o verso alexandrino quanto o pentâmetro compartilham a característica de poderem ser divididos em dois hemistíquios perfeitamente simétricos. Determinada essa escolha, restava definir o metro substituto do hexâmetro. Comparadas três possibilidades (versos de 14, 15 ou 16 
sílabas), o verso de quinze sílabas mostrou-se o mais adequado para acomodar a carga semântica do original, ao mesmo tempo em que mantinha um ritmo fluente e compatível com os padrões da poesia em língua portuguesa.

Mais importante que a definição da extensão do verso, porém, foi a determinação do acento obrigatório na sétima sílaba, a fim de opor o primeiro verso do dístico ao segundo, em que o acento alexandrino na sexta sílaba reproduzia justamente o caráter cataléptico (ou seja, truncado) do pentâmetro latino, contraposto ao hexâmetro. Em outras palavras: enquanto o terceiro pé do hexâmetro é completo, no pentâmetro ele é interrompido, e a pausa é antecipada; portanto, a fim de fazer a correspondência dessa interrupção no verso em português, antecipou-se o acento tônico para a sexta sílaba (graças ao emprego do verso alexandrino); consequentemente, a percepção de que o hexâmetro tem uma fluência e uma continuidade maior que o pentâmetro é garantida, no português (numa tentativa de equivalência), pelo acento tônico posicionado mais adiante, na sétima sílaba, posteriormente abreviada para a sexta sílaba, no verso seguinte.

Uma vez definido o metro, procuramos reproduzir todas as figuras dispostas em função das cesuras, como antíteses e polissíndetos, além de conferir uma atenção especial para a posição das palavras ou das expressões ao longo dos dísticos. Por exemplo, no primeiro verso, mantivemos "filho" entre "mel" e "Vênus", como no original (Mella Puer Veneris), recobrindo o "Amor" de suas qualidades sedutoras. Também procuramos manter repetições e referências, como no uso de "pequenina" e "pequena" para imitar o par perexiguaelexigua do original.

Em termos de sentido, Antônio de Gouveia enfatizou dois aspectos que eram apresentados de modo mais neutro no original grego: a) a relação do Amor com Vênus, salientando sua filiação por meio da reiteração de palavras (inexistentes no grego) que o associam a ela, como Veneris/Venerem e Puer/Nate, além da repetição em versos consecutivos do termo Mater (no grego, apenas uma vez); b) a índole ferina do Amor, cuja força violenta e brutal é reforçada por

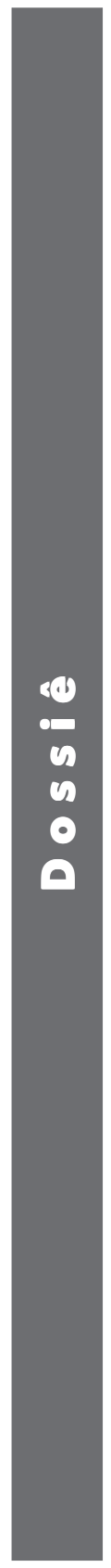


três palavras que Gouveia acrescentou em sua tradução/recriação: uis, infligis e saeua: a primeira indica poder, violência ou aplicação de força física coerciva; a segunda é o verbo "infligir", mais enfático e marcado que "fazer"; a terceira é o adjetivo "cruéis", "terríveis". Em nossa segunda proposta de tradução, procuramos justamente reproduzir os desvios realizados pelo tradutor quinhentista.

Um elemento que chama a atenção no poema de Gouveia é o uso do verbo lego, legere, em diptoto, no primeiro verso (legeret e legenti). Esse verbo, em latim, significa tanto "colher" quanto "ler", apontando para uma leitura metapoética do poema: o puer é um jovem leitor que se deixa tocar pela pungência do texto, um poema curto, de apenas oito versos, mas que, assim como a abelha, é capaz de fisgar quem o lê, produzindo um efeito muito superior ao seu tamanho. Cabe lembrar que essa associação é corroborada pela tradição do gênero epigramático, que costuma reservar para o final do poema a "ferroada" surpreendente e brilhante, sendo que, desde os tempos antigos, foi assumida essa semelhança com a figura da abelha. Nesse caso, no entanto, não conseguimos reproduzir plenamente no português a ambiguidade do latim, ainda que tenhamos optado pelo uso do verbo "colher", cujo dígrafo na segunda sílaba o afasta sonoramente de seu étimo "ler".

Um último detalhe da poética gouveiana (e neolatina em geral), presente na versão renascentista, é a emulação de frases da Literatura Latina na composição de seus poemas. Em nossa tradução não deixamos de notar que o final do quarto verso alude ao início do verso 69, da Écloga X de Virgílio, "omnia uincit Amor". Nesse sentido, procuramos ecoar, em nossa tradução ("o Amor então vencer"), a frase virgiliana traduzível por "o Amor a tudo vence". Dessa forma, incorporamos uma prática visível nesse trecho do texto latino, que é a utilização, na tradução, de material literário muitas vezes posterior ao do texto original traduzido, especialmente quando a obra posterior apresenta algum vínculo com a predecessora, como é o caso de Virgílio em relação a Teócrito. Todos esses aspectos podem ser observados na tradução $B$, apresentada a seguir. 
Finalmente, quando se comparam nossas duas propostas de tradução, é possível perceber como a segunda soa mais artificial e rebuscada, em comparação com a primeira, mais fluente, simples e mais afeita ao ritmo e à melodia da poesia brasileira, espelhando a mesma diferença que há entre o poema de Teócrito, de elocução mais simples e fluente, e a tradução latina, impregnada de figuras, mais artificiosa, mais ciosa de seu papel de tour de force a anunciar a maitrise de seu compositor, e ainda portadora de um comentário metalinguístico intencional. Na sua tradução, o humanista Antônio de Gouveia, em lugar de simplesmente transpor para o latim o texto grego (aproveitando-se da proximidade das duas línguas declinadas), apropriou-se da matéria do poema original, adaptando-o ao gosto e ao estilo da Literatura Neolatina de sua época, reconstruindo-o a partir dos referenciais modelares fornecidos pela Literatura Latina Clássica, num esforço de recriação digno de estudo. 
Ricardo da Cunha Lima. Um idílio grego traduzido parn o latim no Renascinento:...

\title{
Textos Originais
}

Idílio 19, de Teócrito

\section{KHPIOK $\Lambda$ EПTH $\Sigma$}

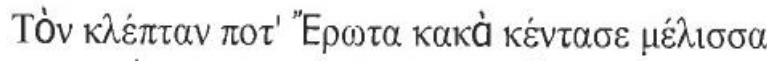

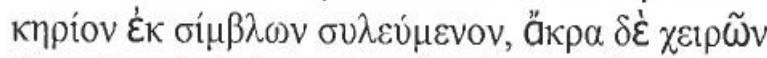

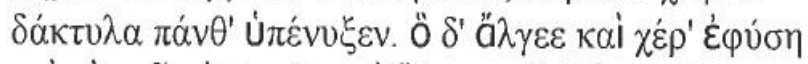

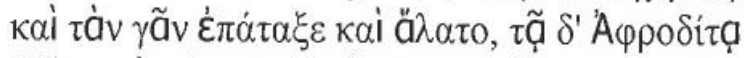

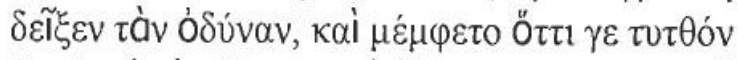

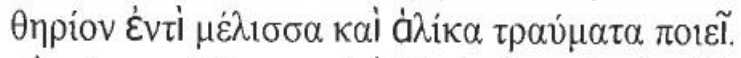
$\chi a ́$ ㅅ́

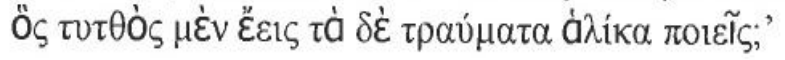

Epigrama 17, de Antônio de Gouveia

\author{
ICTVS AMOR \\ E Graeco Theocriti
}

Mella Puer Veneris legeret cum forte, legenti

Extremos digitos noxia fixit apis.

Exclamat, terramque ferit, flatuque dolorem

Frigidulo ignitum uincere temptat Amor.

Sic gemebundus adit Venerem, cui, respice, dixit,

Magna perexiguae uulnera, Mater, apis.

Cui Mater, tibi uis est, Nate, simillima: namque

Exigua infligis uulnera saeua manu. 


\section{Tradução A}

\section{O amor ladrão (ou A fera ferida)}

O Amor roubava mel de uma colmeia, Quando uma abelha brava the picou A pontinha dos dedos. Ele grita, Assopra, salta, chuta e mostra a Vênus A mão, dizendo: "Mãe, que ferimento Grande a pequena abelha me causou!" Sua mãe riu: "Tu és igual à abelha:

Pequeno, causas grandes ferimentos."

\section{Tradução B \\ O Amor ferido}

(Versão de um poema em grego de Teócrito)

Quando estava a colher mel, ao filho de Vênus ferroou,

Bem na ponta do dedo, uma abelha feroz.

Ele grita, e chuta a terra, e tenta o Amor então vencer,

Com um sopro friozinho, a ardente e forte dor.

Gemendo foi até Vênus, e disse: “Olha, mãe, que ferida

Tão grande a pequenina abelha fez em mim!"

Sua mãe lhe respondeu: "Teu poder é idêntico, filho:

Tua pequena mão faz terríveis feridas." 
Ricardo da Cunha Lima. Um idílio grego traduzido para o latim no Renascimento:...

\section{Referências}

Bucoliques Grecs: Tome I: Théocrite. Paris: Les Belles Lettres, 1946.

Bucoliques Grecs: Tome II: Pseudo-Théocrite. Paris: Les Belles Lettres, 1927.

A Hellenistic Anthology. Selected and edited by Neil Hopkinson. Cambridge: CUP: 1990.

GOUVEIA, Antônio de. Antonii Goueani Lusitani Epigrammaton Libri Duo. Lugdunum (Lyon), 1539.

Antonii Goueani Epigrammata. Eiusdem Epistolae Quattuor. Lugdunum (Lyon), 1540.

LAURENS, Pierre. L'abeille dans l'ambre. Paris, Les Belles Lettres, 1989.

MURARASU, D. La poésie néolatine et la renaissance des lettres antiques en France (1500-1549). Paris, J. Gamber, 1926.

TEÓCRITO. "Idilio XIX" in Bucólicos Griegos. Introducciones, traducciones y notas por Manuel García Teijeiro y Ma. Teresa Molinos Tejada. Madri: Gredos, 1986.

TEÓCRITO. Theocritus: a selection. Edited by Richard Hunter. Cambridge: CUP, 1999.

VIRGÍlIO. Eclogues. Edited by Robert Coleman. Cambridge: CUP, 1998. 